\title{
EUBREWNET RBCC-E Huelva 2015 Ozone Brewer Intercomparison
}

\author{
Alberto Redondas ${ }^{1,2}$, Virgilio Carreño ${ }^{1,2}$, Sergio F. León-Luis ${ }^{1,3}$, Bentorey Hernández-Cruz ${ }^{2,3}$, \\ Javier López-Solano ${ }^{1,2,3}$, Juan J. Rodriguez-Franco ${ }^{1,3}$, José M. Vilaplana ${ }^{4}$, Julian Gröbner ${ }^{5}$, John Rimmer ${ }^{6}$, \\ Alkiviadis F. Bais ${ }^{7}$, Vladimir Savastiouk ${ }^{8}$, Juan R. Moreta ${ }^{9}$, Lamine Boulkelia ${ }^{10}$, Nis Jepsen ${ }^{11}$, Keith M. Wilson ${ }^{12}$, \\ Vadim Shirotov ${ }^{13}$, and Tomi Karppinen ${ }^{14}$ \\ ${ }^{1}$ Izaña Atmospheric Research Center, Agencia Estatal de Meteorología, Tenerife, Spain \\ ${ }^{2}$ Departamento de Ingeniería Industrial, Universidad de La Laguna, Tenerife, Spain \\ ${ }^{3}$ Regional Brewer Calibration Center for Europe, Izaña Atmospheric Research Center, Tenerife, Spain \\ ${ }^{4}$ National Institute for Aerospace Technology - INTA, Atmospheric Observatory "El Arenosillo", Huelva, Spain \\ ${ }^{5}$ Physikalisch-Meteorologisches Observatorium Davos/World Radiation Center, Davos, Switzerland \\ ${ }^{6}$ Centre for Atmospheric Sciences, School of Earth and Environmental Sciences, The University of Manchester, Oxford Road, \\ Manchester M13 9PL, UK \\ ${ }^{7}$ Laboratory of Atmospheric Physics, Aristotle University of Thessaloniki, Thessaloniki, Greece \\ ${ }^{8}$ International Ozone Services, Toronto, Canada \\ ${ }^{9}$ Agencia Estatal de Meteorología, Madrid, Spain \\ ${ }^{10}$ National Meteorological Office, Algeria \\ ${ }^{11}$ Danish Meteorological Institute, Copenhagen, Denmark \\ ${ }^{12}$ Kipp \& Zonen, Delft, The Netherlands \\ ${ }^{13}$ Scientific and Production Association "Typhoon”, Obninsk, Russia \\ ${ }^{14}$ Finnish Meteorological Institute, Sodankylä, Finland
}

Correspondence: Alberto Redondas (aredondasm@aemet.es)

Received: 21 December 2017 - Discussion started: 2 January 2018

Revised: 22 June 2018 - Accepted: 25 June 2018 - Published: 6 July 2018

\begin{abstract}
From 25 May to 5 June 2015, the 10th regional intercomparison campaign of the Regional Brewer Calibration Center - Europe (RBCC-E) was held at El Arenosillo atmospheric sounding station of the Instituto Nacional de Técnica Aeroespacial (INTA). This campaign was jointly conducted by COST Action ES1207 EUBREWNET and the Area of Instrumentation and Atmospheric Research of INTA. A total of 21 Brewers, 11 single- and 10 double-monochromator instruments from 11 countries participated and were calibrated for total column ozone (TOC) and solar UV irradiance. In this 2015 campaign we have introduced a formal approach to the characterisation of the internal instrumental stray light, the filter non-linearity and the algorithm for correcting for its effects on the TOC calculations. This work shows a general overview of the ozone comparison and the evaluation of the correction of the spectral stray light effect for the single-
\end{abstract}

monochromator Brewer spectrophotometer, derived from the comparison with a reference double-monochromator Brewer instrument. At the beginning of the campaign, 16 out of the 21 participating Brewer instruments agreed within better than $\pm 1 \%$, and 10 instruments agreed within better than $\pm 0.5 \%$ considering data with ozone slant column between 100 and $900 \mathrm{DU}$, which does not require instrumental stray light correction.

\section{Introduction}

The fully automated Brewer Spectrophotometer (Brewer, 1973; Kerr et al., 1985; Kerr, 2010) is, together with the Dobson ozone spectrophotometer, the backbone of the World Meteorological Organization (WMO) ozone observation net- 
work, providing high-quality total ozone column (TOC) data for more than 30 years, and it is now deployed at 200 groundbased TOC monitoring stations worldwide. It is also capable of measurements of ozone vertical profiles (Umkehr method), spectral UV radiation and aerosol optical depth in the UV range (AOD-UV), as well as columns of other trace constituents such as sulfur dioxide and nitrogen dioxide.

In November 2003 the WMO/GAW Regional Brewer Calibration Center - Europe (RBCC-E) was established at the Izaña Atmospheric Observatory (IZO) of the Agencia Estatal de Meteorología (AEMET) in Tenerife (Canary Islands, Spain). The RBCC-E consists of calibration laboratory facilities and reference-maintenance equipment mainly composed of three Brewer spectrophotometers, the so-called IZO Triad. This includes a regional primary reference (Brewer no. 157), a regional secondary reference (Brewer no. 183), and a regional travelling reference (Brewer no. 185) that can be transported for calibration campaigns outside IZO. Initially, the RBCC-E transferred the calibration from the World Reference Triad in Toronto. However, due to uncertainties in the future maintenance of the World Triad, in 2011, the WMO scientific advisory group (WMO-SAG) authorised the RBCC-E to transfer its own calibration obtained by the Langley method.

RBCC-E regular intercomparisons are held annually, alternating between Arosa in Switzerland, and the El Arenosillo sounding station of the Instituto Nacional de Técnica Aeroespacial (INTA) at Huelva in the south of Spain. Since 2005, a total of 130 Brewer ozone spectrophotometer calibrations have been performed in these campaigns (see the campaign reports at the RBCC-E website, http://rbcce.aemet.es, and the GAW reports of the VII, Redondas et al., 2015, VIII, Redondas and Rodriguez-Franco, 2016 and IX, Redondas and Rodriguez-Franco, 2015b intercomparison campaigns). In addition to the regular intercomparisons, the RBCC-E performs two types of campaigns supported by the ESA (European Space Agency) validation projects: the NORDIC campaigns, with the objective to study the ozone measurements at high latitudes, and the absolute calibration campaigns performed at IZO with the participation of Brewer and Dobson reference instruments. Figure 1 shows the number of Brewer instruments calibrated at these campaigns since 2003.

The aim of COST Action 1207 EUBREWNET is to establish a coherent network of European stations equipped with Brewer spectrophotometers for the monitoring of total ozone column, spectral UV radiation, and aerosol optical depth in the UV spectral range, ensuring sustainable operation in the long term (Rimmer et al., 2018). Among the primary aims of EUBREWNET is to harmonise operations and develop approaches, practices and protocols to achieve consistency in quality control, quality assurance and coordinated operations, as well as to eliminate duplication of efforts at individual stations. It also aims to establish knowledge exchange and training, and to open up a route to link with international agencies and other networks globally.

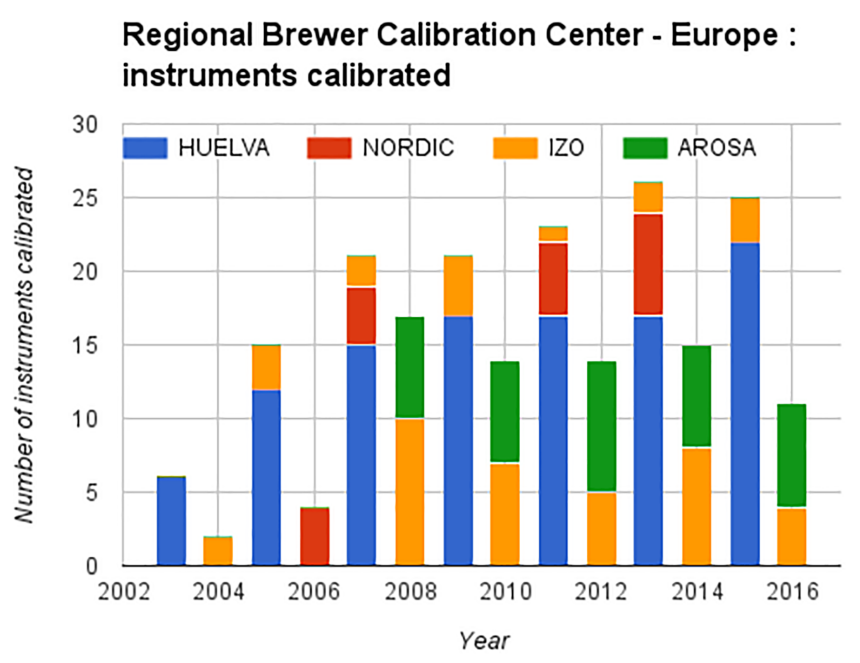

Figure 1. Brewer instruments calibrated since 2003 by the RBCC-E in regular campaigns (at Huelva and Arosa), Nordic intercomparisons and the absolute calibrations performed at the Izaña Observatory.

It was proposed by Fioletov et al. (2008) that the main problem of the Brewer network was the lack of QA/QC, the non-uniformity of the data processing and the lack of reprocessing of the observations after the calibration. This problem is also aggravated because there are more than 100 agencies providing Brewer data with different calibration practices, operational procedures and data processing, including many of the stations within Europe. The intercomparisons are a basic tool to achieve EUBREWNET objectives; in particular during RBCC-E calibration campaigns the instruments perform a common measurement schedule and the observations are uniformly processed and can be used to organise operator training on applying uniform operational procedures. During these campaigns we are able to address some important issues which affect the Brewer performance; these include instrumental parameters and the calibration methodology (Redondas and Rodriguez-Franco, 2012)

Before the establishment of the RBCC-E, the Brewer spectrophotometer calibrations were referenced to the Brewer World Calibration Center hosted by Environment and Climate Change Canada (ECCC). However, most of the Brewer instrument were, and still are, calibrates by private companies, in the main by International Ozone Services (IOS) and to a lesser extent by Kipp \& Zonen (Staehelin, 2010). The RBCC-E calibration adapts the methodologies and tools developed by EC and IOS, but also investigates and improves particular issues. The focus in the first campaigns was on the instrument characterisation and the ozone absorption calculation (Redondas and Rodriguez-Franco, 2012), whereas in this campaign the focus was on the stray light correction and the investigation of the error due to non-linear filter attenuation. 


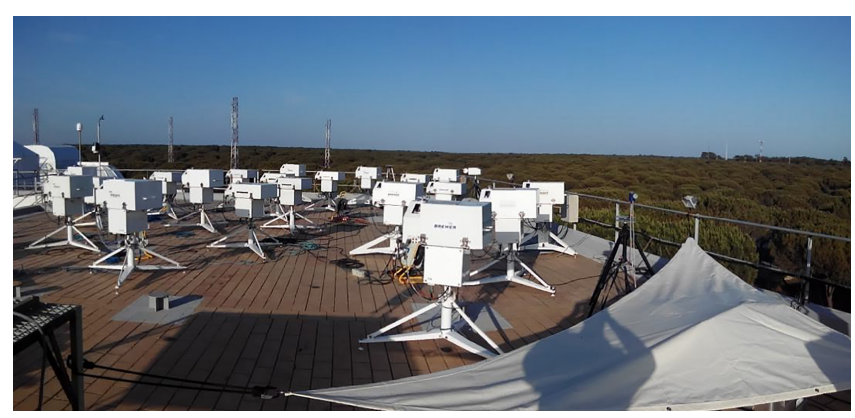

Figure 2. Panoramic view of the 21 Brewer spectrophotometers on the terrace of the El Arenosillo sounding station, Huelva, coming from Canada (1), the Netherlands (2), the United Kingdom (3), Switzerland (1), Finland (1), Greece (1), Denmark (2), Russia (1), Algeria (1) and Spain (7).

The EUBREWNET RBCC-E Huelva 2015 Ozone Brewer Intercomparison campaign had two main objectives: to establish the current status of the network with the participation of about the half of the participating Brewers in the network and to test the improvements introduced during the COST action on the total ozone processing (the stray light correction on single Brewer and the attenuation filter corrections). As well as ozone calibration, solar UV irradiance calibration was also performed by the travelling reference standard QASUME instrument of the World Calibration Center for UV (WCC-UV) and is described by the companion paper by Lakkala et al. (2017); also, it is remarkable that this campaign provided the AOD-UV (López-Solano et al., 2018).

The present work is organised as follows. The Brewer algorithm for TOC and the calibration methodology implemented during the RBCC-E campaigns is described in Sect. 2, with a focus on the improvements introduced by the stray light and the filter corrections. In Sect. 3 we describe and present the results of the intercomparisons. In the blind days section we check the stability of the TOC for the approximately 2-year period between calibrations, and the final days subsection shows the agreement of the instrument at the end of the campaign. In Sect. 4 we discuss the results and the implications of the correction introduced by the EUBREWNET processing and provide some closing remarks.

\section{The calibration of the Brewer spectrophotometer}

A brief description of the instrument and its operating principles in relation to the calibration is described in this section. A more detail description can be found in Kerr (2010) and Savastiouk (2006).

The Brewer instrument measures the intensity of direct sunlight at six wavelengths $(\lambda)$ in the UV $(303.2,306.3$, $310.1,313.5,316.8$ and $320.1 \mathrm{~nm}$ ), each covering a bandwidth of $0.5 \mathrm{~nm}$ (resolution power $\lambda / \delta \lambda$ of approximately $600)$. The spectral measurement is achieved by a holographic grating in combination with a slit mask that selects the channel to be analysed by a photomultiplier. The longest four wavelengths are used for the ozone calculation. The basic ozone measurement is the direct sun measurement. The sunlight enters the instrument through an inclined quartz window after which a right-angle prism directs the incoming light to the optical axis of the instrument. The light subsequently passes through the fore-optics, which consist of a set of lenses to adequately focus the beam, an iris diaphragm and two filter wheels. A ground quartz diffuser is located on the first filter wheel. The second filter wheel consists of a set of five neutral density filter attenuators which guarantee that the detector is working in its linear regime. After passing through the filter wheels, radiation is then focused onto the entrance slit of the monochromator. Presently, there are three commercially available installed Brewer models. The oldest model MKII is a single monochromator with a solar-blind filter, a $\mathrm{NiSO}_{4}$ element sandwiched between two UG-11 glass filters and located between the exit slit and the PMT to block radiation at wavelengths longer than about $325 \mathrm{~nm}$. The model MKIV is capable of measuring $\mathrm{NO}_{2}$; this instrument works with its grating in the third diffraction order for the ozone retrievals and the second diffraction order in $\mathrm{NO}_{2}$ retrievals. However, both instruments are affected by stray light, mainly because of using a single monochromator. In contrast, the model MKIII is a double monochromator which provides enough stray light rejection to work in the first diffraction order for UV and ozone measurements.

Based on the Lambert-Beer law, the total ozone column in the Brewer algorithm can be expressed as (Kerr, 2010)

$X=\frac{\mathrm{ETC}-F}{\alpha \mu}$,

where $F$ is a linear combination of the logarithm of the measured spectral direct irradiances (also called double ratios) corrected for Rayleigh molecular scattering, $\alpha$ is the ozone differential absorption coefficient, $\mu$ is the ozone air mass factor and ETC is the extraterrestrial constant. The $F, \alpha$ and ETC parameters are weighted functions at the operational wavelengths:

$F=\sum_{i}^{4} w_{i} F_{i}-\frac{p}{p_{0}} \beta_{i} \mu$,

$\alpha=\sum_{i}^{4} w_{i} \alpha_{i}$,

$\mathrm{ETC}=\sum_{i}^{4} w_{i} F_{0 i}$,

where $\beta_{i}$ are the Rayleigh coefficients, $p$ is the climatological pressure at the measurement site, $p_{0}$ is the pressure at sea level, and $F_{i}$ and $F_{0 i}$ are the individual measured and extraterrestrial irradiances at each wavelength respectively. The four longer wavelengths $(310.1,313.5,316.8$ and 
$320.1 \mathrm{~nm}$ ) are used on the ozone calculation with the respective weights of $w=[1,-0.5,-2.2,1.7]$. These wavelengths have been selected near stationary points in the ozone absorption spectrum and are thus optimized to minimise the influence of small wavelength shift (i.e. $\delta F / / \delta \lambda=0$ ). The weightings were determined to suppress the influence of $\mathrm{SO}_{2}$ and aerosol. Moreover, as $\lambda_{i}$ and $w_{i}$ satisfy the conditions defined by Eqs. (5) and (6), the measurement not no depend on wavelength-independent parameters such as the absolute calibration. Also, it largely eliminates absorption processes which depend, to first approximation, linearly on the wavelength such as the contribution from aerosols (Kerr, 2010).

$$
\begin{aligned}
& \sum_{i}^{4} w_{i}=0 \\
& \sum_{i}^{4} w_{i} \lambda_{i} \approx 0
\end{aligned}
$$

The Brewer retrieval of the TOC requires the knowledge of some instrument characteristics that are determined by calibration experiments during intercomparison campaigns ( $\mathrm{Re}-$ dondas et al., 2015; Redondas and Rodriguez-Franco, 2015a; Redondas and Rodriguez-Franco, 2015b, see for example the GAW reports of the Seventh, Eighth, and Ninth Intercomparison Campaigns of the RBCC-E). The instrumental calibration includes all the parameters that affect the counts measured by the spectrometer $\left(F_{i}\right)$, in particular the dead time correction (Fountoulakis et al., 2016), temperature coefficients (Berjón et al., 2018) and filter attenuations. The wavelength calibration determines the ozone absorption and Rayleigh scattering coefficients. The exact wavelengths measured by each Brewer spectrophotometer are slightly different from instrument to instrument. The so-called "dispersion test" is thus used to determine the exact wavelengths of each instrument and its slit, or instrumental, function (Gröbner et al., 1998; Redondas et al., 2014a). An extraterrestrial (calibration) constant is determined by the Langley method (Redondas et al., 2014b; León-Luis et al., 2018), in the case of reference brewers, or by comparison with a reference instrument in the case of the other Brewer of the Network.

It is important to note that TOC is then finally determined using ratios of measurements so there is no transfer of the radiometric scale. During the campaigns the transfer of the calibration to a network instrument is achieved by operating side by side with the reference Brewer. Once we have collected enough near-simultaneous direct sun ozone measurements, we calculate the new extraterrestrial constant after imposing the condition that the measured ozone will be the same for simultaneous measurements for both instruments. In terms of Eq. (1), this leads to the following condition:

$\mathrm{ETC}_{j}=F_{j}+X_{j}^{\text {reference }} \alpha \mu_{j}$

For a correctly characterised network instrument, the determined ETC values show a Gaussian distribution and the mean value is used as the instrument's extraterrestrial constant. One exception to this rule is the single-monochromator Brewer models (MK-II and MK-IV), which are affected by stray light (Karppinen et al., 2015). In this case, the ETC distribution shows a tail at the lower ETC values for high ozone slant column (OSC, the product of the total ozone content by the air mass). As we discuss in detail in the next section for this type of Brewer, only the stray-light-free region is used to determine the ETC, which generally ranges from 300 to 800 DU in the OSC, depending on the instrument.

The network Brewers were calibrated using the oneparameter ETC transfer method: i.e. the ozone differential absorption coefficient was derived from the calculations of wavelength calibration, the so-called "dispersion test" (Redondas et al., 2018), applied to the spectroscopic set of the ozone cross section, and only the ozone ETC constant was transferred from the reference instrument. The so-called "two-parameter calibration method" (Staehelin et al., 2003), where both the ozone absorption coefficient and the ETC are calculated from the reference, is also obtained and used as a quality indicator.

The calibration is an iterative process because changes during the instrumental and/or wavelength calibration will affect the final ETC. Some instrumental characteristics which have been improperly accounted for, such as the non-linearity of the filters and the dead-time mismatch (Rodriguez-Franco et al., 2014), are revealed by the comparison with the reference during the ETC transfer. A change in the instrumental constants then requires a full reprocessing of the calibration. For this reason the calibration campaigns are scheduled in three different periods:

1. Blind days. The first days of the campaign are dedicated to determining the current status of the instrument by comparison with the reference instrument. During this period modifications of the instrument are not allowed.

2. Characterisation. After the determination of how the instrument is measuring, the next days are dedicated to characterising the instrument and performing the necessary adjustments and maintenance. The instrumental and wavelength calibration must be finished at the end of this period.

3. Final days. The period where the ETC transfer is performed, when the instrument is fully characterised and stable.

The changes in the spectral sensitivity of the instruments are tracked between calibration transfers using the measurements of the internal quartz halogen lamp, the so-called standard lamp (SL) test. A value, corresponding to a fictitious column density and often called R6, R5 or F ratio (depending on whether the ozone, sulfur dioxide or nitrogen dioxide processing algorithm is applied), is obtained after processing. Slow variations of the SL test results with time may be 


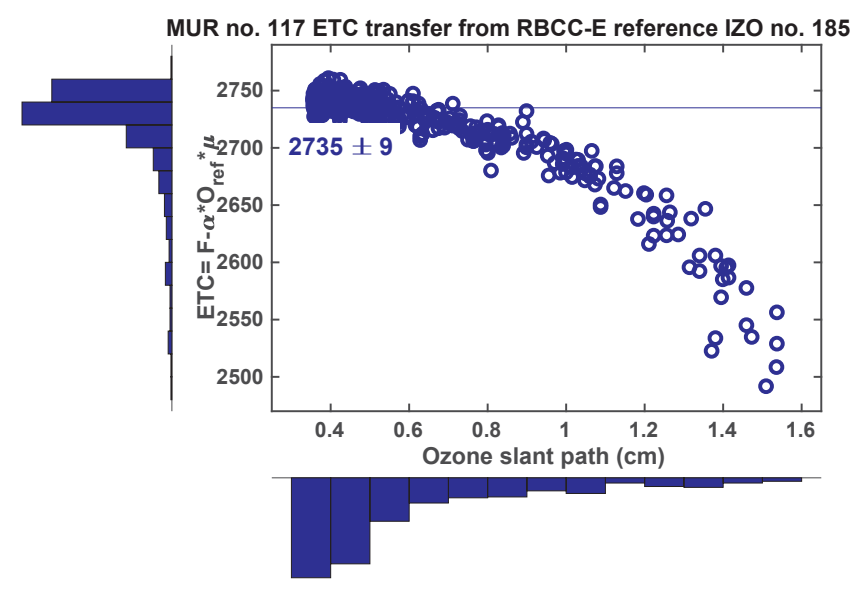

Figure 3. Distribution of individual ETC values determined by simultaneous measurements. The ozone slant column (OSC) is shown on the horizontal axis. For this particular Brewer, the effect of the stray light is strong and clearly shown at values above $0.6 \mathrm{~cm}$.

representative of a change in the relative spectral (but not absolute, because of the way the retrieval algorithm works) sensitivity of the Brewer and may be even used to correct the final value of the solar measurements. This test is performed routinely to track the spectral response of the instrument and, therefore, the ozone calibration. A reference value for the SL, the so-called R6 ratio, is provided as part of the calibration of the instrument. The ozone is routinely corrected assuming that deviations of the R6 value from the reference value are the same as the changes in the ETC extraterrestrial constant. This is then described by the standard lamp correction:

$\mathrm{ETC}_{\text {new }}=\mathrm{ETC}_{\text {old }}-\left(\mathrm{SL}_{\mathrm{ref}}-\mathrm{SL}_{\text {measured }}\right)$.

\subsection{Stray light}

There are two major sources of stray light on the Brewer: the "sky-scattered" and the "out-of-band" stray light; both of them produce an underestimation on the ozone calculation. The sky-scattered stray light is due to the instrument having a field of view (FOV) larger than the apparent angle subtended by the sun in the sky, approximately $0.5^{\circ}$, whereas the instrument FOV is about $1.5^{\circ}$; the measurement will thus include a sky-scattered component (Josefsson, 2003, 2012).

The second source of stray light is due to the finite dimensions of the exit slits and imperfections on the gratings or other optical components so that the intensity measured contains radiation from other unwanted wavelengths. The higher level of stray light in single monochromators increase the error of the measured UV radiation compared with the double monochromators. This effect is largest at short UV wavelengths where the spectral irradiance level is low compared with the level of potential stray light. It is known to affect the Brewer spectral UV measurement (Kerr and McElroy, 1993;
Bais et al., 1996) but only relatively recently has the effect on the ozone calculation been studied (Bojkov et al., 2008; Kiedron et al., 2008; Evans et al., 2009; Petropavlovskikh et al., 2011). The effect on the ozone calculation is enhanced when the short wavelength proportion is decreased due to a high slant path or high ozone content. The air mass in combination with the total ozone amount gives a measure of the absorption of the UV photons and is the key parameter for the stray light. There have been several attempts to model the stray light (e.g. Karppinen et al., 2015; Pulli et al., 2018 and the references within) but this requires the use of models or characterisation of the instruments that are not always available. Here we propose an empirical method based on the comparison of a double Brewer.

The stray light effect can be corrected if the calibration is performed against a double monochromator instrument, assuming that it can be characterised following a power law of the ozone slant column:

$F=F_{\mathrm{m}}+k(X \mu)^{s}$,

where $F$ is the true weighted ratios (Eq. 2), $F_{\mathrm{m}}$ is the measured ones and the $k$ parameter is negative. This is equivalent to correcting the extraterrestrial constant.

$\mathrm{ETC}_{i}=\mathrm{ETC}_{0}+k(X \mu)^{s}$,

where $\mathrm{ETC}_{0}$ is the ETC for the OSC region free of stray light, and $k$ and $s$ are retrieved from the reference comparison (Fig. 4). These parameters, determined in several campaigns, have been found to be stable and independent of the ozone calibration.

As the counts $(F)$ from the single Brewer instrument are affected by stray light, the ozone is calculated using an iterative process:

$X_{i+1}=X_{i}+\frac{k\left(X_{i} \mu\right)^{s}}{\alpha \mu}$.

This empirical method was tested during the NORDIC campaigns and the counterpart campaigns at Izaña with the MKII Brewer no. 037 operated by the Finish Meteorological Institute at Sodankylä (Finland) since 1988 (Karppinen et al., 2016). This instrument was calibrated 4 times at Izaña in 2009, 2011 and 2015 and at Sodankylä in 2011 (Roozendael et al., 2013b, 2014). From these measurement campaigns we found the stray light correction obtained during the first campaign can be applied to the subsequent campaigns, obtaining a good agreement (better than $0.5 \%$ on the $300-1800$ OSC range). This is confirmed with the agreement of the determination of the stray light parameters $k$ and $s$ obtained during different campaigns (Table 3 of Roozendael et al., 2014) at different locations with quite different sky conditions and even with changes in spectral response of the instrument. A similar experiment was done at Huelva with a good agreement using the previous campaign determination of the stray light parameters. 


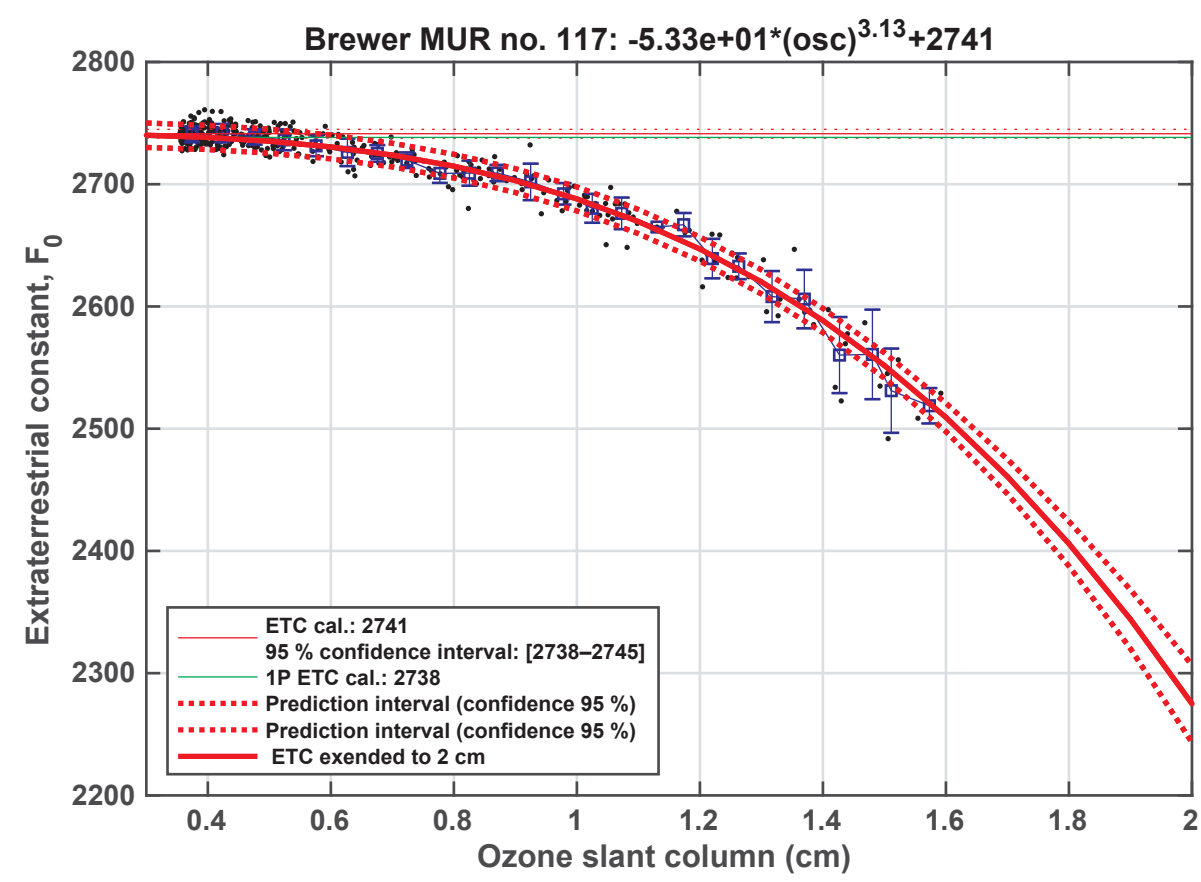

Figure 4. The stray light parameters $k$ and $s$ are determined by a non-linear fit using the ETC determined from the stray-light-free region as first-guess parameters. The red horizontal lines indicate the ETC constant retrieved from the fit, and the green one indicates the initial guess. The upper and lower $95 \%$ prediction bounds are also displayed in red dot lines.

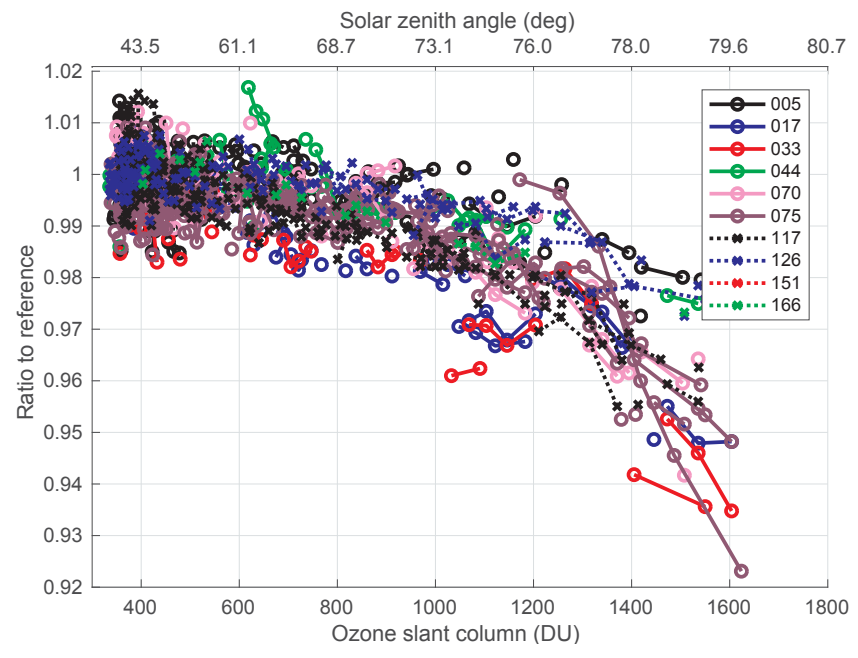

Figure 5. Percentage ozone differences with respect to the reference of the participating Single Brewers. On the upper $x$ axis the approximate solar zenith angle is indicated assuming TOC of $300 \mathrm{DU}$.

Figure 5 shows the ratio of the TOC calculated by a single Brewer participating in the campaign with respect to reference instrument, where we can see that the stray-light-free region that we use for calibration ends for some instruments at $600 \mathrm{DU}$ and is almost evident at 1000DU. The error due to the extrapolation can be estimated from the fit; these error bounds will depend on every instrument and particularly on the extrapolation (Fig. 4). During the Nordic campaign the error bounds for Brewer no. 037 at $2000 \mathrm{DU}$ increases from $\pm 0.25 \%$ if we use observations up to $1600 \mathrm{DU}$ to $1.7 \%$ if we use only observations up to $1200 \mathrm{DU}$. During this campaign with observations up to $1600 \mathrm{DU}$, the error bounds at 2000 DU are lower than $2 \%$ for all the instruments. This results are consistent with the results obtained from the model of Karpinen that shows an error of $1.29 \%$ on the 1900 2000 DU interval (Table 2 of Karppinen et al., 2015). To help the determination of these parameters the measurement schedule is carefully defined to maximise the observations at high OSC, where around $30 \%$ of the simultaneous observations are performed with OSC $>600$ and $15 \%$ are obtained with OSC > 900 DU.

Usually just one iteration is needed for the atmospheric conditions at the intercomparisons carried out at $\mathrm{El}$ Arenosillo, with OSC values up to 1500 DU. For OSC measurements in the 1500-2000 DU range, two iterations are enough to correct the ozone (Fig. 7). These stray light corrections are now implemented in the standard procedure of EUBREWNET.

The effect of the stray light has been studied in the Sodankylä total ozone series, one of the longest records in the Arctic (Roozendael et al., 2014). At this location even at noon the ozone slant column can be quite large. When the model from Karppinen et al. (2015) is applied to the series the effect on the monthly means is significant in spring but there is a marginal effect on the trends. The compari- 
Table 1. Principal investigators and instruments participating on the X RBCC-E campaign.

\begin{tabular}{llrll}
\hline No. & Country & Brewer & Participants & \\
\hline 1 & Greece & 005 & Alkis Bais & Thessaloniki University \\
2 & Canada & 017 & Volodia Savastiouk & International Ozone Services \\
3 & Spain & 033 & Juan R. Moreta & AEMET, State Meteorological Agency from Spain \\
4 & Russia Federation & 044 & Vadim Shirotov & Scientific and Production Association “Typhoon" \\
5 & Spain & 070 & Juan R. Moreta & AEMET, State Meteorological Agency from Spain \\
6 & UK & 075 & John Rimmer & Manchester University \\
7 & Spain & 117 & Juan R. Moreta & State Meteorological Agency from Spain \\
8 & UK & 126 & John Rimmer & Manchester University \\
9 & Spain & 150 & J. M. Vilaplana & National Institute for Aerospace Technology \\
10 & Spain & 151 & Juan R. Moreta & State Meteorological Agency from Spain \\
11 & The Netherlands & 158 & Oleksii Marianenko & Kipp \& Zonen \\
12 & Switzerland & 163 & Julian Gröebner & Physikalisch-Meteorologisches Observatorium Davos \\
13 & Spain & 166 & Juan R. Moreta & AEMET, State Meteorological Agency from Spain \\
14 & UK & 172 & John Rimmer & Manchester University \\
15 & Spain & 185 & Alberto Redondas & Izaña Atmospheric Research Center,AEMET \\
16 & Spain & 186 & Juan R. Moreta & AEMET,State Meteorological Agency from Spain \\
17 & Algeria & 201 & Bukelia Lamine & National Meteorological Office \\
18 & Denmark & 202 & Paul Eriksen & Danish Meteorological Institute, \\
19 & Finland & 214 & Tomi Karpprinen & Finnish Meteorological Institute \\
20 & Denmark & 228 & Niss Jepsen & Danish Meteorological Institute, \\
21 & The Netherlands & 230 & Keith M. Wilson & Kipp \& Zonen \\
\hline
\end{tabular}

son between the empirical correction and the model shows a good agreement $(0.1 \%)$ in most of the operative range, but the model underestimated above $1600 \mathrm{DU}$, reaching $1 \%$ at 2000 DU.

\subsection{Correction of filter non-linearity}

The Brewer spectrophotometer uses neutral density filters in order to optimise the intensity of the light which reaches the photomultiplier. The ozone is calculated using ratios so if the filters are neutral they have no effect on the ozone calculation (Eq. 5). In addition the weighing coefficients also verify Eq. (6) so a linear attenuation with wavelength also does not affect the ozone calculation. In a real instrument however, some of the filters are not neutral, the ozone wavelengths vary from instrument to instrument and the second condition is only an approximation. The effect on the calculated ozone will depend on the filter used (Savastiouk, 2006; Redondas et al., 2011). This dependence is clear when the instrument is compared with a reference and the comparison is seen to depend on the filter (Fig. 6). Differences up to 20 ETC units (up to $4 \%$ in ozone) have been observed during the campaign.

This error can be corrected if we know the spectral dependence of the filter $\mathrm{AF}_{i}$ and introduce a correction dependent on the filter used $(f \#)$ :

$F(f \#)=F_{\mathrm{m}}+\sum_{i=1}^{4} w_{i} \mathrm{AF}(f \#)_{i}$,

where $F$ is the true weighted ratios (Eq. 2) and $F_{\mathrm{m}}$ is the measured ones.
The effect on ozone is only important at low air masses, where the ozone calculation is more dependent on the ETC, which implies high solar signal and in consequence high attenuation filters used.

Several methods have been developed to determine the wavelength dependence of the filter, using the internal lamp or the sun as the source. However, as it affects high attenuation filters, there is not enough signal with the lamp, and the non-linearity is difficult to determine with precision. Frequently the results are not significant with the number of tests that can be performed during a campaign, and the comparison with a well characterised instrument is the preferred method during the inter-comparisons. Also, we can determine the correction directly by examining the record of the instrument and looking for the simultaneous measurements performed with consecutive filters or determine the ETC constant for every filter.

\section{Intercomparison results}

\subsection{The X RBCC-E campaign}

From 25 May to 5 June 2015, 21 Brewer spectrophotometers from 11 countries (see Table 1) took part in the X RBCCE campaign held at the El Arenosillo atmospheric sounding station (Huelva, Spain). Besides the ozone calibration, a solar UV irradiance calibration was performed by the travelling reference standard QASUME (Hülsen et al., 2016) instrument of the World Calibration Center for UV (WCC- 

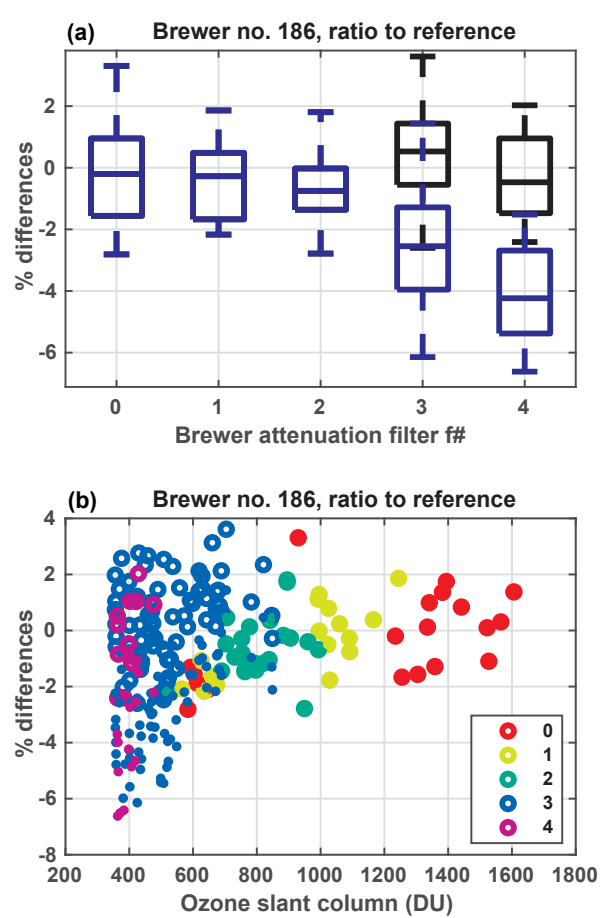

Figure 6. Box plot of the percentage differences with respect to the reference grouped by filter for Brewer no. 186, in blue without correction, and in black after applying the correction to filters 3 and 4 (a). Panel (b) shows percentage differences with respect to the reference grouped by filter, without correction (solid dots), and after the application of the correction to filters 3 and 4 (open circles). Colours indicate the number of the filter; see the legend.

UV). The X RBCC-E campaign was the result of the collaboration between COST Action 1207 EUBREWNET (http: //www.eubrewenet.org/cost1207) and the Area of Instrumentation and Atmospheric Research of INTA (Redondas et al., 2016).

El Arenosillo Atmospheric Sounding Station, which belongs to the National Institute for Aerospace Technology (INTA), is located on the Atlantic Coast, in the province of Huelva in the region of Andalusia, in south-west Spain. Its surroundings correspond to the Doñana National Park, which guarantees its natural environment. Moreover, the climate at El Arenosillo is characterised by very frequent sunny conditions, around 280 clear sky days per year, making it a really suitable site for intercomparison campaigns. The observatory has a big terrace with completely open horizon (Fig. 2). The surroundings of the station consist of pine trees which provide a uniform albedo spatially and temporally throughout the whole year. This constant behaviour of the albedo allows the comparability of results obtained in different seasons and years.

During the campaign we collected $\approx 650$ direct sun ozone measurements with the reference instrument, most of them $(\approx 65 \%)$ being within the $300-600 \mathrm{DU}$ ozone slant path

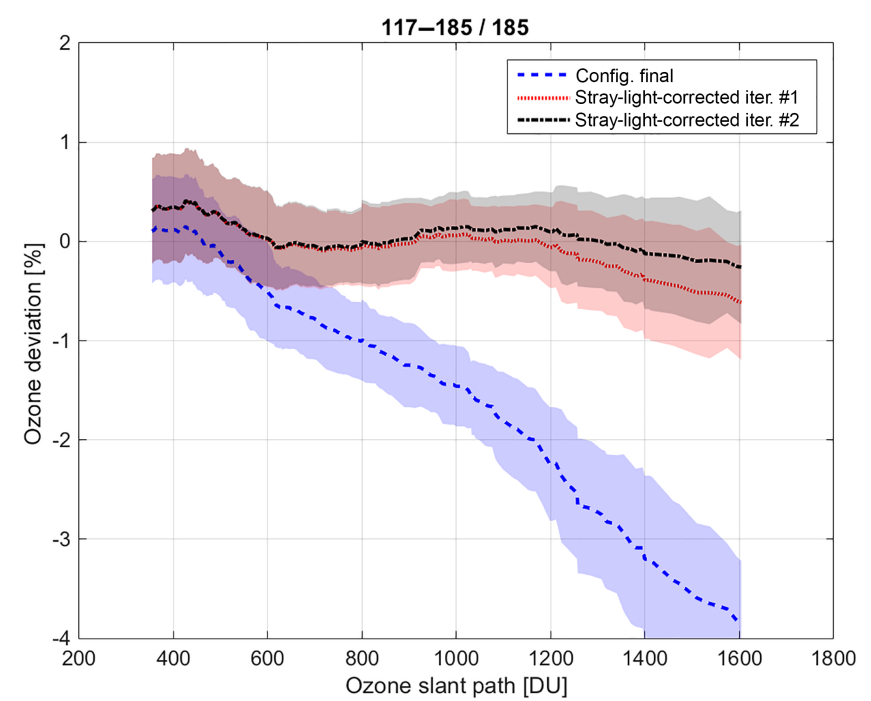

Figure 7. Percentage ozone differences with respect to the reference vs. ozone slant path. In blue, using the final configuration constants, and in black and red, after the stray light correction has been applied, with one and two iterations, respectively. Data are averaged in $\pm 50 \mathrm{DU}$ intervals; the shadow area represents 1 standard deviation.

range, with $18 \%$ in the 600-900 DU range and $17 \% 900$ $1700 \mathrm{DU}$ range. The mean number of near-simultaneous ozone measurements between the Brewers and the reference instrument was 350 . Total ozone content values at El Arenosillo station during the intercomparison ranged between 320 to $380 \mathrm{DU}$. This campaign was characterised by high internal temperatures, with an average of $32^{\circ} \mathrm{C}$ and a standard deviation of $5^{\circ} \mathrm{C}$, which is $10^{\circ} \mathrm{C}$ above the spectrometer normal operating temperatures (Berjón et al., 2018).

Briefly, the Brewer network is calibrated with two main parameters: the ETC and the effective ozone absorption coefficient. The comparison with a reference instrument is used to establish the ETC but the effective ozone absorption coefficient can also be derived from the reference (two-parameter method), as was done in the past (Staehelin et al., 2003), or directly from wavelength calibration as is performed at present (one-parameter method) (Fioletov et al., 2005). Historically the two-parameter method was used until around the year 2000; after that the one-parameter method has been adopted in the Brewer network. Although both methods give the same results in the 300-800 DU range (stray-light-free range), the two-parameter calibration gives uniform results, smoothing the instrumental differences and reduces the stray light error on a single Brewer (Bojkov et al., 2008). However, the one-parameter calibration is more robust, does not depend on reference wavelength calibration, and highlights instrumental differences. An error in the ETC value yields an error that depends on the solar zenith angle, while an error in effective ozone absorption coefficient introduces a relative bias. The transition in the calibration methodology around 
(a)

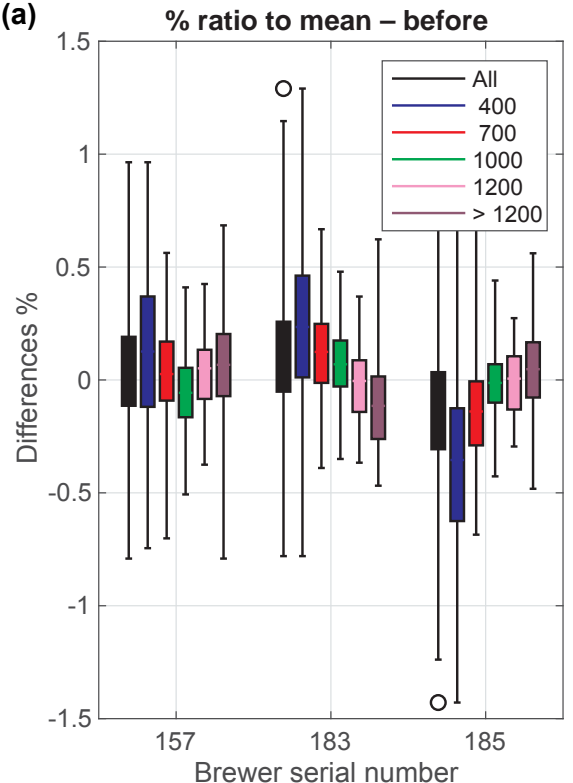

(b)

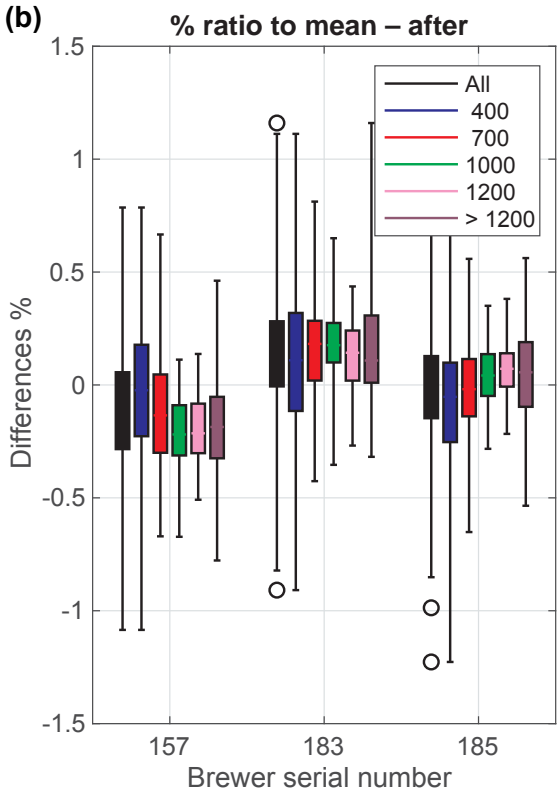

Figure 8. Box plot of the ozone percentage deviation from the mean of the RBCC-E triad reference Brewer no. 157, Brewer no. 183 and Brewer no. 185 before (a) and after (b) the X RBCC-E campaign at El Arenosillo in 2015, grouped by ozone slant column ranges. The colour indicates the intervals used for the averaging of the observations - blue, lower than $400 \mathrm{DU}$; red, between 400 and $700 \mathrm{DU}$; green, between 700 and 1000 DU; pink, between 1000 and 1200 DU; and purple for OSC > 1200 DU. In black is shown the average of all observations.

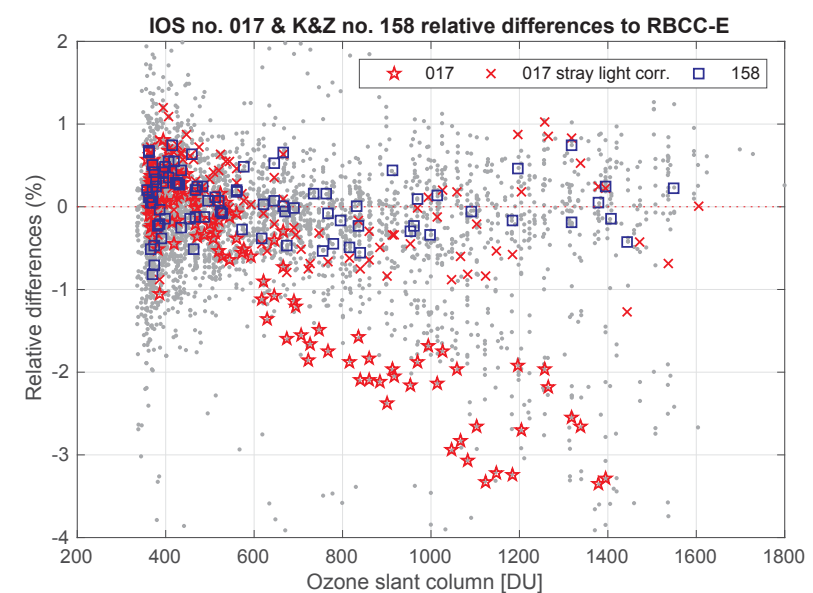

Figure 9. Comparison of reference instruments during the $X$ RBCC-E campaign: relative differences with respect to the IZO reference using the initial configuration during the campaign, in red for the IOS Brewer no. 017 (stars are used for the original observations and crosses for the stray light corrected ones), and in blue for the Kipp \& Zonen (K\&Z) Brewer no. 158. The gray points are the relative differences to the IZO reference for all participating instruments

the year 2000 can explain the change in the seasonal difference between ground-based Brewers and satellites observed by Fioletov et al. (2008). During the RBCC-E campaigns we can show that the two-parameter calibration can mask instrumental issues which are air-mass dependent. Moreover,

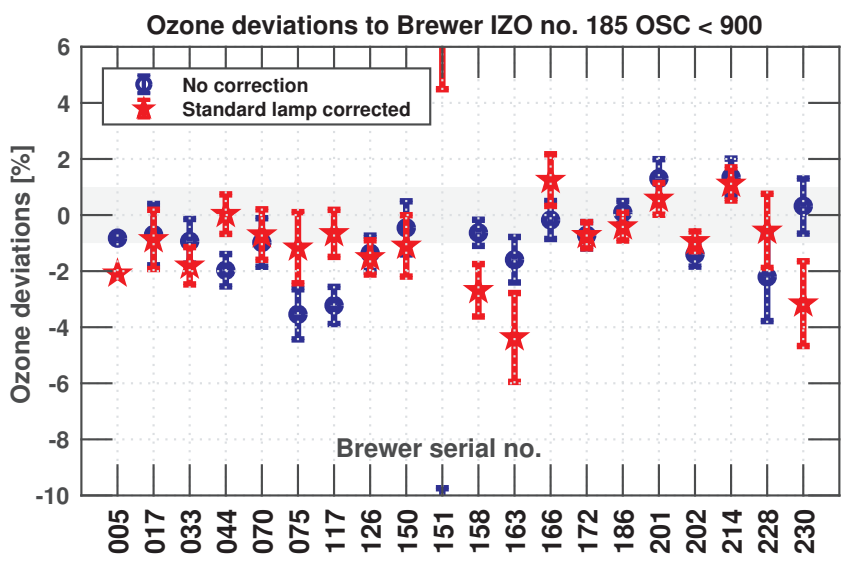

Figure 10. Percentage mean difference for the simultaneous direct sun measurements with the reference for all the participating instruments, with and without the standard lamp correction, in the straylight-free OSC region (OSC < 900). (The Brewer no. 151 is an not operative brewer, is not providing reliable data, and is outside the limits.)

both calibration methods give the same results on well characterised instruments and the difference between the calibration constants can be used as an indicator of the quality of the instrument calibration (Redondas and Rodriguez-Franco, 2012; Roozendael et al., 2014). 
Table 2. Reference comparison during RBCC-E campaigns, the Brewer no. 017 is the travelling reference from International Ozone Service (IOS), the Brewer no. 158 is the travelling reference from Kipp \& Zonen and finally Brewer no. 145 from Environmental Canada is a double Brewer and direct calibrated to the World Reference Triad, which participates on the previous RBCC-E campaigns.

\begin{tabular}{lrrrrl}
\hline Location & Year & No. 017 & No. 158 & No. 145 & Report \\
\hline Arosa & 2008 & -0.6 & & & Redondas and Rodriguez-Franco (2008) \\
Huelva & 2009 & -0.6 & 0.8 & -0.1 & $\begin{array}{l}\text { Roozendael et al. (2012) } \\
\text { Arosa }\end{array} 2010$ \\
Huelva & 2011 & -0.6 & & & Roozendael et al. (2013b) \\
Arosa & 2012 & & -0.1 & -0.6 & Roozendael et al. (2013a) \\
Huelva & 2013 & -1.0 & -0.1 & & Redondas et al. (2015) \\
Izaña & 2014 & & & -2.2 & $\begin{array}{l}\text { Redondas and Rodriguez-Franco (2015a) } \\
\text { Arosa }\end{array}$ \\
Huelva & 2014 & -1.2 & 1.5 & & $\begin{array}{l}\text { Redondas et al. (2014b) } \\
\text { this work }\end{array}$ \\
\hline
\end{tabular}

\subsection{Reference calibration}

The RBCC-E triad is regularly calibrated, performing the instrumental characterisation and wavelength calibration monthly. The three instruments are independently calibrated by the Langley plot method following the procedure described in Redondas et al. (2014b) and León-Luis et al. (2018). Before and after the intercomparison campaigns, the travelling instrument is compared with the two static instruments to verify that the calibration has not changed during transport (Fig. 8, Redondas et al., 2015; Redondas and Rodriguez-Franco, 2015a; Redondas and Rodriguez-Franco, 2015b; León-Luis et al., 2018).

The campaign is a good opportunity to compare travelling reference instruments, that is, instruments that are used to transfer calibrations. Brewers no. 017, managed by International Ozone Services and directly calibrated to the Environment and Climate Change Canada, Toronto Triad (Fioletov et al., 2005; Fioletov and Netcheva, 2014; Netcheva, 2014), and no. 158, managed by Kipp \& Zonen, manufacturer of the Brewer spectrophotometer, took part in the X RBCC-E campaign. Since 2007 the Brewer no. 158 is calibrated annually during the RBCC-E intercomparisons so it is already referenced to the RBCC-E triad. The calibration of the IOS and RBCC-E triads primary reference for the travelling instruments is discussed by León-Luis et al. (2018).

The agreement between the travelling reference instruments during this campaign was found to be quite good, with differences lower than $0.5 \%$ for OSC lower than $900 \mathrm{DU}$ (see Table 2, Fig. 9). Note that Brewer no. 017 is a singlemonochromator instrument and is affected by stray light, thus underestimating the ozone at high OSC values above 600 DU.

Table 2 shows the comparison of the reference instruments during the RBCC-E campaigns and the corresponding calibration report. The agreement is generally around $\pm 0.5 \%$, but with exceptions, in contrast to the RBCC-E travelling instrument, which is transported by boat or car to Huelva and in the cabin of the plane as hand luggage, to Arosa campaigns.
The travelling instrument is usually transported by cargo and can have issues during transportation that are reflected in Table 2 or require instrumental changes for example no. 158 had a new PMT and new electronics during Arosa 2014, and the SL tests do not reflect this change.

\subsection{Blind days}

A blind comparison with the reference Brewer instrument is performed at the beginning of the campaign, thus providing information on the initial status of the instrument, i.e. how well the instrument performs using the original calibration constants (those operational at the instrument's station). Possible changes in the instrument response due to the travel can be detected through the analysis of internal tests performed before and after the travel.

The analysis of the SL historical record is one of the principal tools to establish the stability of the instrument calibration. Moreover, the comparison with a reference during calibration campaigns is the most suitable tool to determine whether the observed R6 changes are related to changes in the ETC constant or not. During the El Arenosillo 2015 intercomparison campaign, most instruments agreed on average with the corresponding R6 reference value within \pm 10 units, which is about $1 \%$ in ozone. The stray light record tracks small and slow changes in instrument responsivity well but has issues when these changes are abrupt or huge. Generally, from our experience, the SL correction tracks the changes in the relative spectral sensitivity of the Brewers well unless the instrument characteristics change (whether intentionally or not) in ways that affect the ozone observations differently from the SL measurements, e.g. changes in the iris diaphragm, neutral density filters, or zenith prism pointing towards the lamp or the sun. During the analysis we focus on the instruments that showed deviation from the reference that is larger than 20 units (Fig. 11). Even in these cases for some instruments, for example Brewer no. 228, the SL correction improves the comparison; in contrast, for others, such as no. 163 , where the change was produced by the modifica- 
(a) Arenosillo, Huelva (Spain), 27 May-5 June 2015

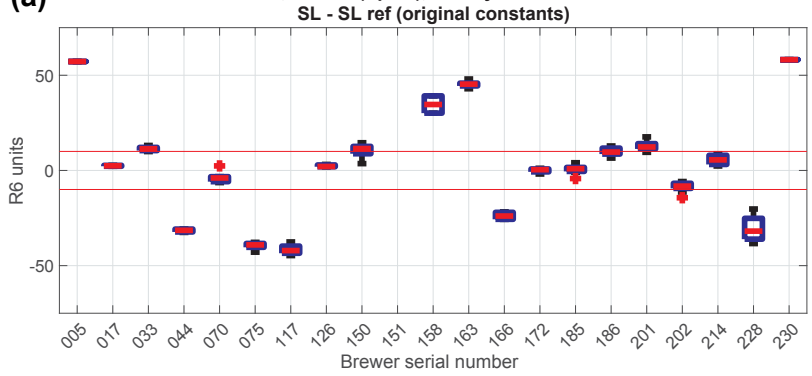

(b)

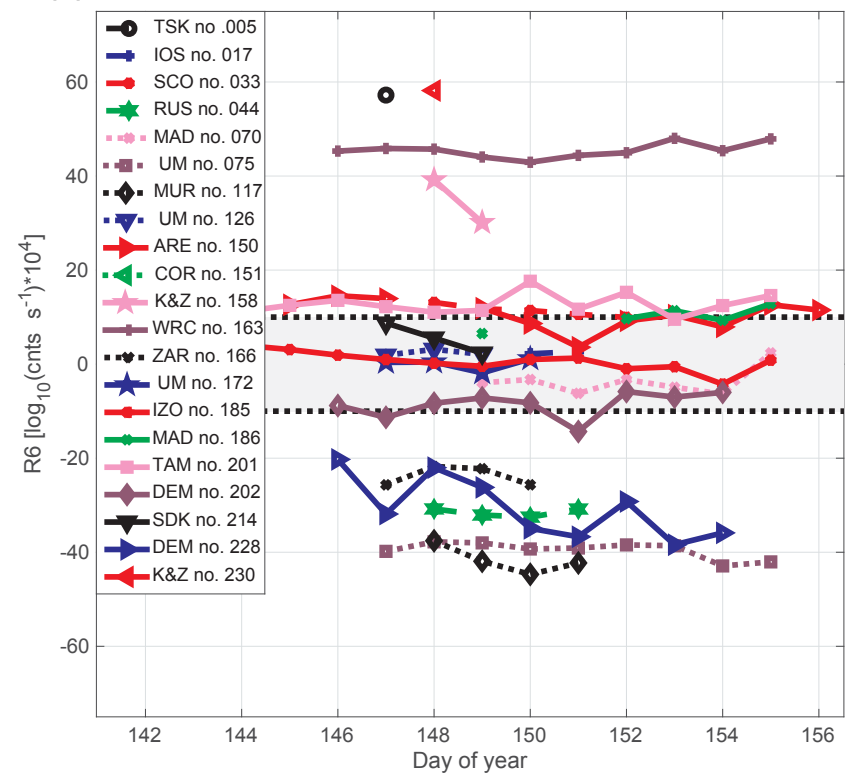

Figure 11. Standard lamp R6 difference with respect to the R6 reference value from the last calibration during the blind days, before the maintenance. The upper panel shows the mean value for each instrument and the lower panel the daily mean during the campaign. Variations within the \pm 10 units range ( $\sim 1 \%$ in ozone) from the reference value are considered normal, whereas larger changes would require further analysis of the instrument performance.

tion of the fore-optics, the opposite happens. The comparison with a standard reference instrument is the only way to assess whether the SL correction properly tracks changes in the calibration or the changes observed are just due to changes of the lamp's spectral emission (Fig. 10). This analysis will determine if a re-evaluation of the ozone observations between calibrations is required after an analysis of the history of the instrument.

In the following analysis we do not consider non-operative instruments, an operative instrument is one which is capable of providing reliable data during the campaign suitable for submission to databases like EUBREWNET or WOUDC (World Ozone and UV Data Center). This is not the case of no. 151 because the instrument shows a huge change in the (a)

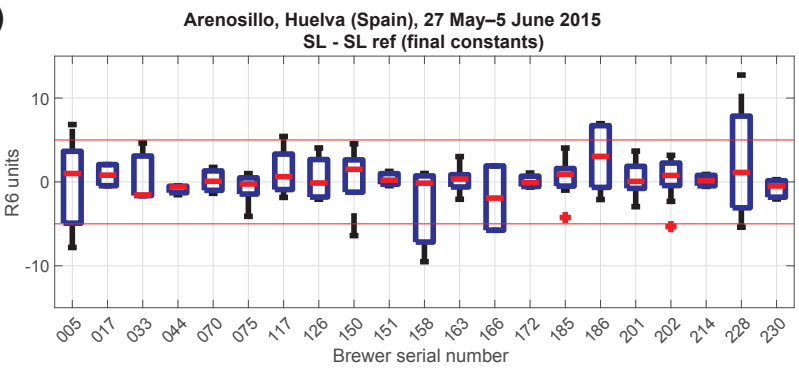

(b)

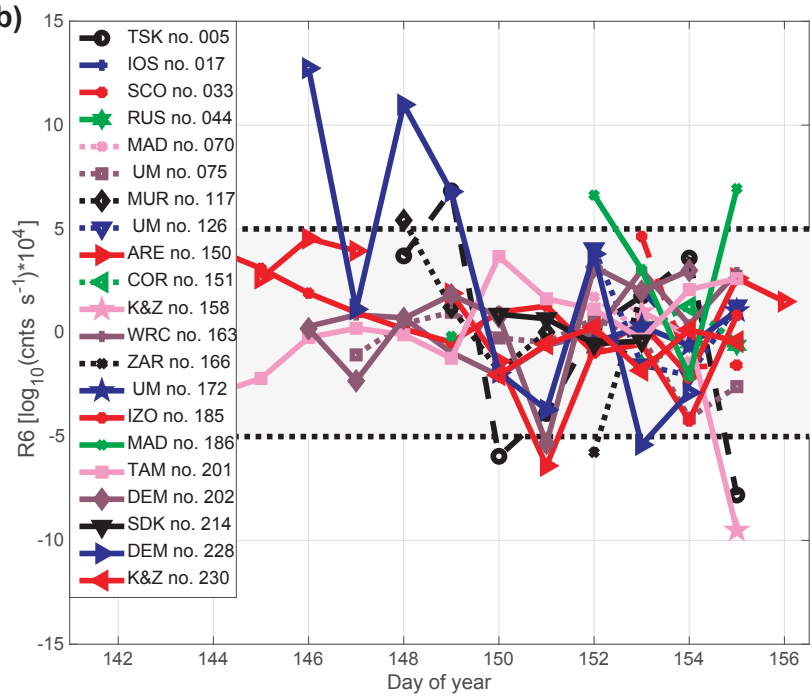

Figure 12. Differences between the daily standard lamp R6 ratio and the proposed R6 reference value during the final days. The upper panel shows the mean value for each instrument, and the lower panel the daily mean during the campaign. It is important to get an stable R6 value during the final days, within the \pm 5 units range ( $\sim .5 \%$ in ozone), to stabilise the reference value of the calibration.

SL record from the last calibration (300 R6 units while the instrument range is $\pm 60 \mathrm{UD}$ ), indicating serious instrumental issues.

Table 3 shows the mean relative difference for the simultaneous direct sun measurements with the reference for all the participating instruments, with and without the standard lamp correction, in the stray-light-free OSC region. With the exception of Brewer no. 151, that can not be considered an operational instrument, the maximum difference found is $1.5 \%$. This is a really good result considering that most of the instruments were calibrated 2 years previously. The third column of the table shows the average of the best result for all the observation OSC range. This result is an estimation of the calibration agreement of the EUBREWNET network, with half of the instruments showing a perfect agreement within $\pm 0.5 \%$, and $75 \%$ within the $\pm 1 \%$ level. 
Table 3. Summary of mean percentage difference before calibration, without and with standard lamp correction, and after the calibration, on the last column with the stray light correction applied.

\begin{tabular}{lrrrrr}
\hline Brewer ID & No corr. & SL corr. & Blind & Final & Stray \\
\hline 005 & - & - & -1.93 & -0.2 & -0.08 \\
017 & -0.31 & -0.49 & -0.98 & -0.95 & 0.11 \\
033 & -0.8 & -1.77 & -1.09 & -1.83 & -0.48 \\
044 & -2.04 & 0.13 & -0.21 & -0.27 & 0.2 \\
070 & -0.73 & -0.42 & -0.71 & -0.53 & 0.18 \\
075 & -3.42 & -0.71 & -1.2 & -0.8 & -0.2 \\
117 & -3.38 & -0.45 & -0.68 & -0.6 & 0.04 \\
126 & -1.25 & -1.41 & -1.36 & -0.29 & -0.08 \\
150 & -0.45 & -1.07 & -0.45 & -0.27 & - \\
151 & -17.36 & 9.94 & 7.95 & 0.67 & 0.83 \\
158 & -0.54 & -2.45 & -0.54 & 0.05 & - \\
163 & -1.5 & -4.16 & -1.5 & -0.06 & - \\
166 & -0.15 & 1.45 & -0.24 & -0.58 & - \\
172 & -0.67 & -0.67 & -0.67 & -0.01 & - \\
186 & 0.13 & -0.34 & 0.13 & -0.05 & - \\
201 & 1.21 & 0.52 & 0.52 & 0.09 & - \\
202 & -1.39 & -0.95 & -0.95 & -0.06 & - \\
214 & 1.42 & 1.19 & 1.19 & -0.01 & - \\
228 & -1.93 & -0.4 & -0.4 & -0.1 & - \\
230 & -0.15 & -3.48 & -0.15 & 0.36 & - \\
\hline
\end{tabular}

\subsection{Final comparison}

We define the final days as those available after the maintenance work has been finished for each participating instrument. These days are used to calculate the final calibration constants, so we endeavour not to manipulate the instruments during this period. Furthermore, the SL R6 value recorded during the final days is normally adopted as the new reference value. It is also expected that this parameter will not vary by more than five units during this period. We show in Fig. 12 the differences between the daily standard lamp R6 ratio and the proposed R6 reference value during the final days. As expected, the recorded SL values did not vary by more than five units during this period.

Deviations of ozone values for all the participating instruments with respect to the RBCC-E travelling standard Brewer no. 185 are shown in Fig. 13 and summarised in Table 3. We have recalculated the ozone measurements using the final calibration constants and, in the case of single Brewer instruments, with and without the stray light correction as described in Sect. 2.

The effect of the stray light correction on the statistics is not large: only $30 \%\left(\right.$ sza $\left.>60^{\circ}\right)$ of the observations are affected on the single Brewer, and for only $15 \%\left(\mathrm{sza}>70^{\circ}\right.$ ) is the effect bigger than $1 \%$, but taking into account the stray light allows for the instruments to be calibrated using the one-parameter method. Not taking into account this correction when using the two-parameter method as in Bojkov et al. (2008) can cause a misleading calibration con-

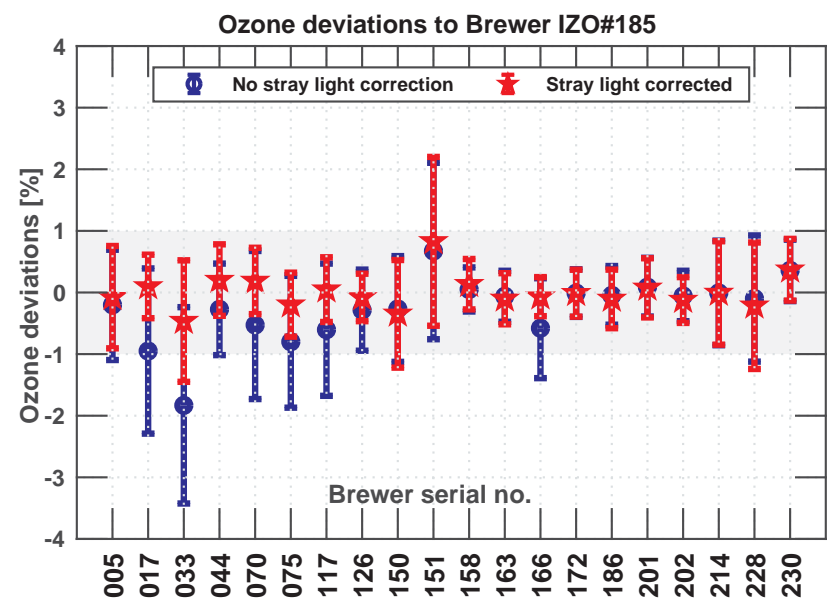

Figure 13. Final days mean percentage difference with respect to the reference Brewer for the simultaneous direct sun measurements for all the participating instruments. Blue circles shows results without the stray light correction and red stars show results with the correction applied to single Brewer spectrophotometers.

stant. For all the instruments, both the one-parameter and the two-parameter ETC transfer methods agreed with each other within the limit of \pm 5 units for ETC constants and $\pm 0.3 \%$ for ozone absorption coefficients, which is an indication of the quality of the calibration provided.

We achieved a good agreement with the reference instrument Brewer no. 185 using the final calibration constants; see Fig. 13 and Table 3. With the application of the stray light correction to the single Brewer spectrophotometers, all instruments are within the $\pm 0.5 \%$ agreement range.

\section{Conclusions}

To summarise the calibration results of the 10th RBCC-E campaign, we found that during the blind days, using the 2year-old calibration issued in the previous campaign,

- 16 Brewer spectrophotometers $(\sim 75 \%$ of the participating instruments) were within the $1 \%$ agreement range,

- 10 Brewer spectrophotometers $(\sim 50 \%)$ were within the $\pm 0.5 \%$ range, i.e. show a perfect agreement, and

- the maximum average error was $1.5 \%$ for operational Brewer instruments within stray-light-free conditions (OSC $<700 \mathrm{DU})$.

These results are in agreement with the RBCC-E campaigns celebrated in Huelva and Arosa from 2009 to 2015 (Fig. 14), in this period 85 spectrometers have been calibrated: $59(69 \%)$ show an agreement better than 1\%, 32 $(38 \%)$ within $0.5 \%$ and $7(8 \%)$ show a discrepancy greater than $2 \%$. 


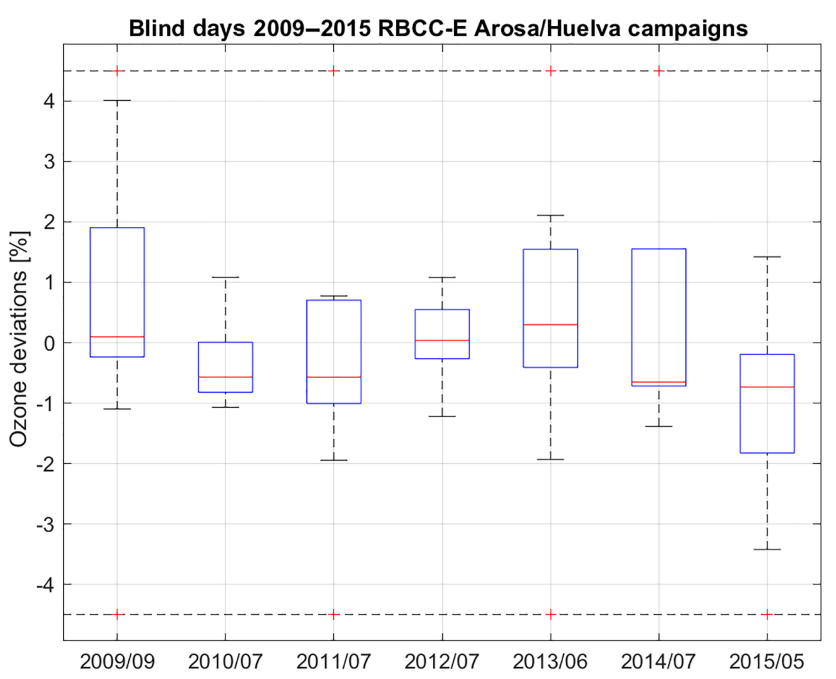

Figure 14. Ozone deviations for the blind days with respect to the reference Brewer for the simultaneous direct sun measurements for all the participating instruments during the RBCC-E regular campaigns 2009-2015. The campaigns performed in odd years correspond to Arosa (Switzerland) and in even years in Huelva (Spain). These results correspond to the stray-light-free region OSC $<700 \mathrm{DU}$; the outliers (red cross at $\pm 4.5 \%$ levels) generally correspond to non-operating instruments.

A participating instruments are calibrated with oneparameter calibration. The one-parameter and two-parameter ETC transfer methods agreed with each other within the limit of \pm 5 units for ETC constants and $\pm 0.3 \%$ for ozone absorption coefficients, indicating a high-quality calibration.

After the new calibration was issued at the end of the $\mathrm{X}$ RBCC-E campaign, we had the following results:

- All participating Brewer spectrophotometers were within the $\pm 0.5 \%$ agreement range.

- Without the implementation of stray light correction, large errors of up to $4 \%$ can be expected for singlemonochromator Brewer instruments operating at OSC larger than $1000 \mathrm{DU}$.

- The implementation of the stray light correction in the calibration of single Brewer instruments improved their performance. Therefore, this correction has been introduced in EUBREWNET for the automatic processing of data sent by single-monochromator Brewers.

Data availability. The data and model codes are available at the RBCC-E website for all the intercomparisons.

Author contributions. AR was primarily responsible for the RBCC$\mathrm{E}$, analysed the data and led the paper preparation. $\mathrm{VC}$ is a researcher of RBCC-E and carried out daily housekeeping and QC of the intercomparison. SFLL is a researcher of RBCC-E, brewer QC, data analysis and contributed to the paper. BHC is Eubrewnet data manager. JLS is a researcher of the RBCC-E and carried out data analysis as well as contributing to the writing of the paper. JJRF is a researcher of the RBCC-E and calibration software programmer and carried out calibration data analysis. JMV is a local organizer of the campaign at INTA/El Arenosillo and IP of Brewer no. 150 and also carried out daily housekeeping and QC. JG is the IP of the QASUME instrument (World Radiation Center), Brewer UV calibration manager, and IP of the Brewer no. 163 and contributed to the writing of the paper. JR is chairman of EUBREWNET, IP of the Brewer no. 075, no. 126 and no. 172 as well as contributing to the writing of the manuscript. AFB is the PI of the Brewer no. 005 and contributed to the writing of the paper. VS is the PI of the Brewer no. 017 and contributed to the writing of the paper. JRM is the PI Brewer no. 033, no. 070, no. 117, no. 151 and no. 186 . LB is the Brewer no. 165 PI and carried out daily housekeeping and QC. NJ is the Brewer no. 202 and no. 228 and carried out daily housekeeping and QC. KMW is the Brewer no. $158 \mathrm{PI}$ and carried out daily housekeeping and QC. VS is the Brewer no. 044 PI and carried out daily housekeeping and QC. TK is the Brewer no. 214 PI and carried out daily housekeeping and QC and contributed to the paper.

Competing interests. Keith Wilson is an employee of Kipp \& Zonen, the manufacturer of the Brewer spectrometer used in this study. Vladimir Savastiouk is the president of International Ozone Service a company that provides Brewer calibrations.

Acknowledgements. All this work would have not been possible without the participation, work and dedication of all the Brewer operators in the RBCCE intercomparison campaigns.

This article is based upon work from COST Action 1207 EUBREWNET, supported by COST (European Cooperation in Science and Technology). This work has been supported by the European Metrology Research Programme (EMRP) within the joint research project ENV59 "Traceability for atmospheric total column ozone" (ATMOZ). The EMRP is jointly funded by the EMRP participating countries within EURAMET and the European Union. We also gratefully acknowledge further support by the Fundación General de la Universidad de La Laguna. This study and the campaigns were supported at large part by ESA project CEOS Intercalibration of ground-based spectrometers and lidars (ESRIN contract 22202/09/I-EC).

Edited by: Stefan Reis

Reviewed by: two anonymous referees

\section{References}

Bais, A. F., Zerefos, C. S., and McElroy, C. T.: Solar UVB measurements with the double- and single-monochromator Brewer ozone spectrophotometers, Geophys. Res. Lett., 23, 833-836, https://doi.org/10.1029/96GL00842, 1996.

Berjón, A., Redondas, A., Sildoja, M.-M., Nevas, S., Wilson, K., León-Luis, S. F., El Gawhary, O., and Fountoulakis, I.: Sensitivity study of the instrumental temperature corrections on Brewer 
total ozone column measurements, Atmos. Meas. Tech., 11, 3323-3337, https://doi.org/10.5194/amt-11-3323-2018, 2018.

Bojkov, B. R., Redondas, A., Cede, A., Kyrö, E., Evans, R., and McElroy, T.: SAUNA - Sodankylä Total Ozone Intercomparison and Validation Campaign, Brewer/Dobson Summary, Proceedings of the Quadrennial Ozone Symposium, Troms $\varnothing$, 29 June-5 July 2008, 2008.

Brewer, A. W.: A replacement for the Dobson spectrophotometer?, Pure Appl. Geophys., 106-108, 919-927, https://doi.org/10.1007/BF00881042, 1973.

Evans, R., McConville, G., Oltmans, S., Petropavlovskikh, I., and Quincy, D.: Measurement of internal stray light within Dobson ozone spectrophotometers, Int. J. Remote Sens., 30, 4247-4258, https://doi.org/10.1080/01431160902825057, 2009.

Fioletov, V. and Netcheva, S.: The Brewer Triad and Calibrations; The Canadian Brewer Spectrophotometer Network, http://kippzonen-brewer.com/wp-content/uploads/ 2014/10/Status-of-the-Canadian-Network-Brewer-Triad_

StoykaNetcheva.pdf (last access: 29 June 2018), 2014.

Fioletov, V. E., Kerr, J., McElroy, C., Wardle, D., Savastiouk, V., and Grajnar, T.: The Brewer reference triad, Geophys. Res. Lett., 32, https://doi.org/10.1029/2005GL024244, 2005.

Fioletov, V. E., Labow, G., Evans, R., Hare, E. W., Köhler, U., McElroy, C. T., Miyagawa, K., Redondas, A., Savastiouk, V., Shalamyansky, A. M., Staehelin, J., Vanicek, K., and Weber, M.: Performance of the ground-based total ozone network assessed using satellite data, J. Geophys. Res., 113, https://doi.org/10.1029/2008JD009809, 2008.

Fountoulakis, I., Redondas, A., Bais, A. F., Rodriguez-Franco, J. J., Fragkos, K., and Cede, A.: Dead time effect on the Brewer measurements: correction and estimated uncertainties, Atmos. Meas. Tech., 9, 1799-1816, https://doi.org/10.5194/amt-9-1799-2016, 2016.

Gröbner, J., Wardle, D. I., McElroy, C. T., and Kerr, J. B.: Investigation of the wavelength accuracy of Brewer spectrophotometers, Appl. Opt., 37, 8352-8360, https://doi.org/10.1364/AO.37.008352, 1998.

Hülsen, G., Gröbner, J., Nevas, S., Sperfeld, P., Egli, L., Porrovecchio, G., and Smid, M.: Traceability of solar UV measurements using the Qasume reference spectroradiometer, Appl. Opt., 55, 7265-7275, https://doi.org/10.1364/AO.55.007265, 2016.

Josefsson, W.: Quality of Total Ozone Measured by the Focused Sun Method Using a Brewer Spectrophotometer, J. Appl. Meteorol., 42, 74-82, https://doi.org/10.1175/15200450(2003)042<0074:QOTOMB>2.0.CO;2, 2003.

Josefsson, W.: Focused sun observations using a Brewer ozone spectrophotometer, J. Geophys. Res.-Atmos., 97, 15813-15817, https://doi.org/10.1029/92JD01030, 2012.

Karppinen, T., Redondas, A., García, R. D., Lakkala, K., McElroy, C. T., and Kyrö, E.: Compensating for the Effects of Stray Light in Single-Monochromator Brewer Spectrophotometer Ozone Retrieval, Atmos. Ocean, 53, 66-73, https://doi.org/10.1080/07055900.2013.871499, 2015.

Karppinen, T., Lakkala, K., Karhu, J. M., Heikkinen, P., Kivi, R., and Kyrö, E.: Brewer spectrometer total ozone column measurements in Sodankylä, Geosci. Instrum. Method. Data Syst., 5, 229-239, https://doi.org/10.5194/gi-5-229-2016, 2016.

Kerr, J. B.: The Brewer Spectrophotometer, in: UV Radiation in Global Climate Change, 160-191, Springer, 2010.
Kerr, J. B. and McElroy, C. T.: Evidence for Large Upward Trends of Ultraviolet-B Radiation Linked to Ozone Depletion, Science, 262, 1032-1034, https://doi.org/10.1126/science.262.5136.1032, 1993.

Kerr, J. B., McElroy, C. T., Wardle, D. I., Olafson, R. A., and Evans, W. F. J.: The Automated Brewer Spectrophotometer, in: Atmospheric Ozone, 396-401, Springer, Dordrecht, https://doi.org/10.1007/978-94-009-5313-0_80, 1985.

Kiedron, P., Disterhoft, P., and Lantz, K.: Stray light correction, Algorithms and Procedures, StrayLightCorrection.pdf, http: //esrl.noaa.gov/gmd/grad/neubrew/Documents.jsp\#algo_procs (last access: 29 June 2018), 2008.

Lakkala, K., Arola, A., Gröbner, J., Leon-Luis, S. F., Redondas, A., Kazadzis, S., Karppinen, T., Karhu, J. M., Egli, L., Heikkilä, A., Koskela, T., Serrano, A., and Vilaplana, J. M.: Performance of the FMI cosine error correction method for the Brewer spectral UV measurements, Atmos. Meas. Tech. Discuss., https://doi.org/10.5194/amt-2017-414, in review, 2017.

León-Luis, S. F., Redondas, A., Carreño, V., López-Solano, J., Berjón, A., Hernández-Cruz, B., and Santana-Díaz, D.: Stability of the Regional Brewer Calibration Center for Europe Triad during the period 2005-2016, Atmos. Meas. Tech. Discuss., https://doi.org/10.5194/amt-2017-460, in review, 2018.

López-Solano, J., Redondas, A., Carlund, T., Rodriguez-Franco, J. J., Diémoz, H., León-Luis, S. F., Hernández-Cruz, B., GuiradoFuentes, C., Kouremeti, N., Gröbner, J., Kazadzis, S., Carreño, V., Berjón, A., Santana-Díaz, D., Rodríguez-Valido, M., De Bock, V., Moreta, J. R., Rimmer, J., Boulkelia, L., Jepsen, N., Eriksen, P., Bais, A. F., Shirotov, V., Vilaplana, J. M., Wilson, K. M., and Karppinen, T.: Aerosol optical depth in the European Brewer Network, Atmos. Chem. Phys., 18, 3885-3902, https://doi.org/10.5194/acp-18-3885-2018, 2018.

Netcheva, S.: Canada's Ozone Science Program. 9th Ozone Research Manager's Meeting. Oral Presentation, http: //conf.montreal-protocol.org/meeting/orm/9orm/presentations/ English/1400b_Canada_NationalRpt_9ORM_v3.pdf, 2014.

Petropavlovskikh, I., Evans, R., McConville, G., Oltmans, S., Quincy, D., Lantz, K., Disterhoft, P., Stanek, M., and Flynn, L.: Sensitivity of Dobson and Brewer Umkehr ozone profile retrievals to ozone cross-sections and stray light effects, Atmos. Meas. Tech., 4, 1841-1853, https://doi.org/10.5194/amt-4-18412011, 2011.

Pulli, T., Karppinen, T., Nevas, S., Kärhä, P., Lakkala, K., Karhu, J. M., Sildoja, M., Vaskuri, A., Shpak, M., Manoocheri, F., Doppler, L., Gross, S., Mes, J., and Ikonen, E.: Out-ofRange Stray Light Characterization of Single-Monochromator Brewer Spectrophotometers, Atmos. Ocean, 56, 1-11, https://doi.org/10.1080/07055900.2017.1419335, 2018.

Redondas, A. and Rodriguez-Franco, J.: Eighth Intercomparison Campaign of the Regional Brewer Calibration Center Europe (RBCC-E), no. 223 in GAW Report, World Meteorological Organization, 2015a.

Redondas, A. and Rodriguez-Franco, J.: Ninth Intercomparison Campaign of the Regional Brewer Calibration Center Europe (RBCC-E), no. 224 in GAW Report, World Meteorological Organization, http://library.wmo.int/pmb_ged/gaw_224_en.pdf (last access: 29 June 2018), 2015 b.

Redondas, A. and Rodriguez-Franco, J.: Eighth Intercomparison Campaign of the Regional Brewer Calibration Center for Eu- 
rope (RBCC-E) (El Arenosillo Atmospheric Sounding Station, Heulva, Spain, 10-20 June 2013), Izaña Atmospheric Research Center, AEMET, Tenerife, Canary Islands, Spain, 2016.

Redondas, A. and Rodriguez-Franco, J. J.: AROSA 2008 REPORTS - WikiNesia, Calibration Report, Regional Brewer Calibration Center - Europe, AEMET, http://www.iberonesia. net/index.php/AROSA_2008_REPORTS (last access: 29 June 2018), 2008.

Redondas, A. and Rodriguez-Franco, J. J.: Regional Brewer Calibration Center - Europe CEOS campaigns: Instrumental Findings, in: Quadrennial International Ozone Symposium, Toronto, Canada, http://hdl.handle.net/20.500.11765/7850 (last access: 29 June 2018), 2012.

Redondas, A., Carreno, V., Afonso, S., Rodriguez-Franco, J., Sierra, M., and Almansa, F.: Attenuation filter correction issues on the brewer ozone calculation, comparison of three methods to determine the ozone filter correction, in: The 13th Biennial WMO Brewer Users Group Meeting, World Meteorological Organization, Beijing, China, http://www.wmo.int/pages/prog/arep/gaw/ documents/13th_Brewer_d1_Redondas.pdf (last access: 29 June 2018), 2011.

Redondas, A., Fountoulakis, I., Carreño Corbella, V., Franco, R., and José, J.: Dispersion test results with multiple geometries at RBCC-E campaign AROSA 2014, in: Delft (Países Bajos) del 11 al 12 de noviembre de 2014, Delft, Netherlands, https://repositorio.aemet.es/bitstream/20.500.11765/2604/ 1/DSP_AROSA_2014.pdf (last access: 29 June 2018), 2014a.

Redondas, A., Rodriguez, J., Carreno, V., and Sierra, M.: RBCCE 2014 langley campaign the triad before Arosa/Davos campaing, http://hdl.handle.net/20.500.11765/2599 (last access: 29 June 2018), 2014b.

Redondas, A., Rodríguez-Franco, J., Gröbner, J., Köhler, U., and Stuebi, R.: Seventh Intercomparison Campaign of the Regional Brewer Calibration Center Europe (RBCC-E), no. 216 in WMO/GAW Reports, World Meteorological Organization, http://www.wmo.int/pages/prog/arep/gaw/documents/ Final_GAW_216.pdf (last access: 29 June 2018), 2015.

Redondas, A., Rodriguez-Franco, J. J., López-Solano, J., Carreño, V., León-Luis, S., Hernández-Cruz, B., and Berjón, A.: The Regional Brewer Calibration Center Europe: an overview of the $\mathrm{X}$ Brewer Intercomparison Campaign, in: Quadrenial Ozone Symposium, Madrid, Spain, https://www.wmocimo.net/eventpapers/session1/S(2) _Redondas_RBCC-E_overviewoftheXcampaign.pdf (last access: 29 June 2018), 2016.

Redondas, A., Nevas, S., Berjón, A., Sildoja, M.-M., León-Luis, S. F., Carreño, V., and Santana, D.: Wavelength calibration of Brewer spectrophotometer using a tuneable pulsed laser and implications to the Brewer ozone retrieval, Atmos. Meas. Tech. Discuss., https://doi.org/10.5194/amt-2017-459, in review, 2018.
Rimmer, J. S., Redondas, A., and Karppinen, T.:EuBrewNet - A European Brewer network (COST Action ES1207), an overview, Atmos. Chem. Phys. Discuss., https://doi.org/10.5194/acp-20171207, in review, 2018.

Rodriguez-Franco, J. J., Redondas, A., Sierra, M., and Carreno, V.: Intercomparison campaigns: Instrumental findings, in: Cost Action ES1207 Eubrewnet Open Congress/14th WMO-GAW Brewer Users Group Meeting,2428 March 2014, State Meteorological Agency of Spain, http://www.eubrewnet.org/cost1207/owncloud/public.php?

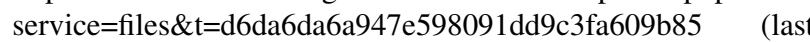
access: 29 June 2018), 2014.

Roozendael, M. V., Köhler, U., Pappalardo, G., Kyrö, E., Redondas, A., Wittrock, F., Amodeo, A., and Pinardi, G.: CEOS Intercalibration of Ground-Based Spectrometers and Lidars: Second Progress Report, Tech. rep., European Space Agency, http: //repositorio.aemet.es/handle/20.500.11765/8889 (last access: 29 June 2018), 2012.

Roozendael, M. V., Köhler, U., Pappalardo, G., Kyro, E., Redondas, A., Wittrock, F., Amodeo, A., and Pinardi, G.: CEOS Intercalibration of Ground-Based Spectrometers and Lidars: Final report, Tech. rep., European Space Agency, http://repositorio.aemet.es/ handle/20.500.11765/8886 (last access: 29 June 2018), $2013 \mathrm{a}$.

Roozendael, M. V., Köhler, U., Pappalardo, G., Kyrö, E., Redondas, A., Wittrock, F., Amodeo, A., and Pinardi, G.: CEOS Intercalibration of Ground-Based Spectrometers and Lidars: Final report, Tech. rep., European Space Agency, http://repositorio.aemet.es/ handle/20.500.11765/8886 (last access: 29 June 2018), $2013 \mathrm{~b}$.

Roozendael, M. V., Kyrö, E., Karppinen, T., Redondas, A., Cede, A., and Hendrick, F.: CEOS Intercalibration of GroundBased Spectrometers and Lidars: Contract Change Notice 20122013: Final Report, Tech. rep., European Space Agency, http: //repositorio.aemet.es/handle/20.500.11765/8909 (last access: 29 June 2018), 2014.

Savastiouk, V.: Improvements to the Direct-Sun ozone observations taken with the Brewer spectrophotometer, PhD Thesis, York University, Toronto, Ontario, 2006.

Staehelin, J.: Total Ozone monitoring by grouddbased instruments as part of GAS, in: TECO-2010 - WMO Technical Conference on Meteorological and Environmental Instruments and Methods of Observation, p. 12, WMO-GAW, Helsinki, https://www.wmo.int/pages/prog/www/IMOP/publications/ IOM-104_TECO-2010/1_3_Stahelin_Switzerland.pdf （last access: 29 June 2018), 2010.

Staehelin, J., Evans, R. D., Kerr, J. B., and Vanicek, K.: Comparison of total ozone measurements of Dobson and Brewer spectrophotometers and recommended transfer functions, GAW/WMO, Report No. 149, 2003. 